\title{
Postulated release profile of recombinant human bone morphogenetic protein-2 (rhBMP-2) from demineralized dentin matrix
}

\author{
In-Woong Um¹, Jeong-Kui Kư ${ }^{2,3}$, Bu Kyu Lee ${ }^{3}$, Pil-Young Yun ${ }^{4}$, Jeong Keun Lee ${ }^{5}$, Jeong-Hun Nam ${ }^{6}$ \\ ${ }^{1} R \& D$ Institute, Korea Tooth Bank, Seoul, \\ ${ }^{2}$ Department of Oral and Maxillofacial Surgery, Section of Dentistry, Armed Forces Capital Hospital, Seongnam, \\ ${ }^{3}$ Department of Oral and Maxillofacial Surgery, Seoul Asan Medical Center, Seoul, \\ ${ }^{4}$ Department of Oral and Maxillofacial Surgery, Section of Dentistry, Seoul National University Bundang Hospital, Seongnam, \\ ${ }^{5}$ Department of Oral and Maxillofacial Surgery, Institute of Oral Health Science, Ajou University School of Medicine, Suwon, \\ ${ }^{6}$ Department of Dental Implant/Oral Surgery, Private Clinic, Seoul, Korea
}

\begin{abstract}
J Korean Assoc Oral Maxillofac Surg 2019;45:123-128)
Demineralized dentin matrix (DDM) has been used as a recombinant human bone morphogenetic protein-2 (rhBMP-2) carrier in many clinical trials. To optimize the clinical safety and efficacy of rhBMP-2 with DDM, efforts have been made to improve the delivery of rhBMP-2 by 1) lowering the administered dose, 2) localizing the protein, and 3) prolonging its retention time at the action site as well as the bone forming capacity of the carrier itself. The release profile of rhBMP-2 that is associated with endogenous BMP in dentin has been postulated according to the type of incorporation, which is attributed to the loosened interfibrillar space and nanoporous dentinal tubule pores. Physically adsorbed and modified, physically entrapped rhBMP-2 is sequentially released from the DDM surface during the early stage of implantation. As DDM degradation progresses, the loosened interfibrillar space and enlarged dentinal tubules release the entrapped rhBMP-2. Finally, the endogenous BMP in dentin is released with osteoclastic dentin resorption. According to the postulated release profile, DDM can therefore be used in a controlled manner as a sequential delivery scaffold for rhBMP-2, thus sustaining the rhBMP-2 concentration for a prolonged period due to localization. In addition, we attempted to determine how to lower the rhBMP-2 concentration to $0.2 \mathrm{mg} / \mathrm{mL}$, which is lower than the approved $1.5 \mathrm{mg} / \mathrm{mL}$.
\end{abstract}

Key words: Collagen, Bone morphogenetic proteins, Demineralized dentin matrix

[paper submitted 2019. 3. 25 / revised 2019. 5. 28 / accepted 2019. 5. 28]

\section{Introduction}

Bone morphogenetic proteins (BMPs) are natural mol-

\section{Jeong-Kui Ku}

Department of Oral and Maxillofacial Surgery, Section of Dentistry, Armed Forces Capital Hospital, 81 Saemaeul-ro 177beon-gil, Bundang-gu, Seongnam 13574, Korea

TEL: +82-31-725-6184 FAX: +82-31-706-0987

E-mail:kujk123@gmail.com

ORCID: https://orcid.org/0000-0003-1192-7066

In-Woong Um

R\&D Institute, Korea Tooth Bank, 622 Eonju-ro, Gangnam-gu, Seoul 06101, Korea

TEL: +82-2-548-2055 FAX: +82-2-548-2228

Email:h-bmp@hanmail.net

ORCID: https://orcid.org/0000-0002-4628-3662

(c) This is an open-access article distributed under the terms of the Creative Commons Attribution Non-Commercial License (http://creativecommons.org/ licenses/by-nc/4.0/), which permits unrestricted non-commercial use, distribution, and reproduction in any medium, provided the original work is properly cited.

Copyright (C) 2019 The Korean Association of Oral and Maxillofacial Surgeons. All rights reserved. ecules that were first identified in dentin and demineralized bone matrix in ectopic sites of rats and are capable of bone formation ${ }^{1}$. In 1968, Urist suggested that these BMPs are released from native dentinal tubules and act as osteoinductive proteins ${ }^{2}$. Since then, several members of the BMP family have been isolated, and BMP-2 has been produced and refined for therapeutic purposes (recombinant human BMP, rhBMP-2) $)^{3,4}$.

In 2007, the United States (US) Food and Drug Administration (FDA) approved rhBMP-2 INFUSE BONE Graft (Medtronics, Memphis, TN, USA) at a concentration of 1.5 $\mathrm{mg} / \mathrm{mL}$ along with an absorbable collagen sponge (ACS) as an alternative to autogenous bone grafting for maxillary sinus grafting and localized alveolar ridge augmentation ${ }^{5,6}$. Collagen is a natural polymer that can be processed into powder, membrane film, liquid, gel, and nanofiber forms and is the most widely used carrier for delivery of rhBMP- $2^{7}$. In general, proteins can be inserted into the pores of ACS immedi- 
ately before grafting by soaking the ACS in rhBMP-2 protein solution (this method is used in commercially available INFUSE) $)^{8}$.

In an in vivo physiological environment, the proteins from the ACS can be released rapidly by diffusion, compression during handling, and/or degradation of the ACS, despite its biocompatibility, biodegradability, and solubility in a physiological environment. Therefore, placing a graft into an environment in which sponges are compressed by the surrounding muscles and tissues might result in local release of unnecessarily large amounts of rhBMP ${ }^{9,10}$.

Several adverse events, including those related to wound healing (hematoma, wound dehiscence, and infection), inflammation (cervical spine swelling), ectopic bone formation (bone cyst formation), osteoclast activity (vertebral bone resorption and osteolysis), and urogenital events (bladder retention), have been reported with the use of BMPs ${ }^{11}$. A common side effect of rhBMP-2/ACS reported in a meta-analysis is ectopic bone formation associated with leakage of rhBMP-2 outside the graft site due to mishandling during manual manipulation of the $\mathrm{ACS}^{11}$. This ectopic bone formation occurs primarily due to the type of rhBMP-2/ACS used in rehabilitation of spine-related disorders. These side effects are known to occur because the above-mentioned dosage is higher than that of osteogenic proteins naturally acting in the human body, and the carrier delivering the protein lacks the ability to maintain the concentration exclusively at the graft site.

The US FDA investigated the safety and effectiveness of localized alveolar ridge and sinus augmentation by comparing 120 oral and maxillofacial surgery patients treated with $1.5 \mathrm{mg} / \mathrm{mL}$ rhBMP-2/ACS and 91 patients treated with autologous bone graft. According to their results, the most common adverse events were oral pain, oral edema, facial edema, and oral erythema. No statistically significant adverse events were reported in patients exposed to rhBMP-2/ACS, but the incidence of facial edema was relatively higher in the rhBMP-2/ACS group ${ }^{12}$. Thus, although the ACSs have been approved and used in humans, the optimal scaffold for delivery of rhBMP-2 in human has not yet been established.

In dentistry, Ike and Urist ${ }^{13}$ hypothesized that demineralized dentin matrix (DDM) collagen of humans can act as an effective carrier of rhBMP-2 to overcome the reported side effects in association with the supraphysiologic concentration of rhBMP-2 $(1.5 \mathrm{mg} / \mathrm{mL})$ and properties of the carrier materi$\mathrm{al}^{13-17}$. Therefore, we describe and propose the release profile of rhBMP-2 from DDM collagen (DDM/rhBMP-2) based on related studies.

\section{Demineralized Dentin Matrix as an rhBMP-2 Carrier}

\section{Human dentin}

The dentin consists of collagen (18\%), hydroxyapatite (70\%), non-collagenous protein ( $2 \%)$, and body fluids $(10 \%)$. It is composed of an avascular, acellular, dense collagen matrix that contains non-collagenous growth factors, such as BMPs. These dentin-matrix-derived BMPs are similar to BMPs derived from the bone matrix, and they have been shown to have identical functions in vivo ${ }^{18,19}$.

The inorganic component of dentin is physiologic calcium phosphate with various degrees of resorbability, which promotes degradation of dentin collagen ${ }^{20}$ and leads to predictable and controlled biodegradation of the dentin matrix ${ }^{21}$.

The dentin matrix contains nano-sized dentinal tubules (1-3 $\mu \mathrm{m}$ in diameter) that are important for release of endogenous
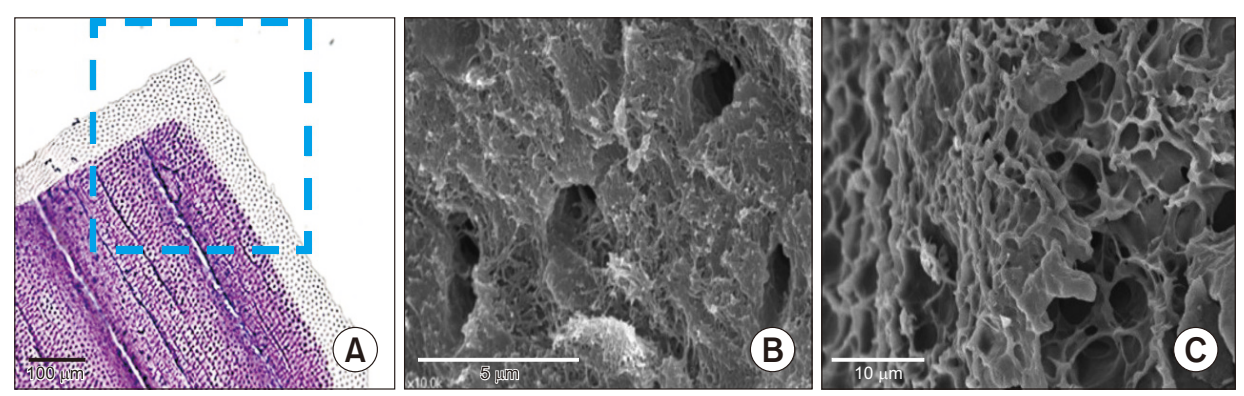

Fig. 1. Surface of demineralized dentin matrix (DDM) powder ${ }^{26}$. A. The surface of the DDM is stained gray due to the dentinal tubules, while the mineralized core is stained violet (H\&E). B. Scanning electron micrography of DDM. The dentinal tubules are enlarged (dentinal tubule pores), and there is loosened surface collagen ${ }^{26}$. C. Scanning electron micrography of DDM. The dense interfibrillar spaces are loosened (interfibrillar space pores) ${ }^{26}$.

In-Woong Um et al: Postulated release profile of recombinant human bone morphogenetic protein-2 (rhBMP-2) from demineralized dentin matrix. J Korean Assoc Oral Maxillofac Surg 2019 
growth factors present in the matrix and of hydroxyapatitebinding proteins. The number of dentinal tubules is 18,000 21,000 (tubules $\left./ \mathrm{mm}^{2}\right)^{22}$. The volume porosity of the dentinal tubule is $3.47 \% \pm 1.46 \%$ on average, which is lower than that of natural bone in humans $(6.2 \%)^{23,24}$.(Fig. 1) In vitro, in vivo, and clinical studies have shown that dentin collagen has superior cell adhesion capacity, excellent tissue compatibility and absorptivity, and weak antigenicity ${ }^{19,25}$.

\section{Demineralized dentin matrix (AutoBT, Korea Tooth Bank, Seoul, Korea)}

The DDM powder is produced from extracted human teeth according to the protocol of the Korea Tooth Bank (Korea Tooth Bank). Briefly, the teeth are divided separated into groups based upon whether they are crowns or tooth roots, and then the tooth roots are crushed to obtain particles 300 $800 \mu \mathrm{m}$ in size. These particles are demineralized with $0.6 \mathrm{~N}$ $\mathrm{HCl}$ for 30 minutes. Through demineralization, the mineral phase and major immunogenic components of the dentin are removed, while maintaining the collagen that plays a structural role as an osteoconductive scaffold and contains soluble protein fractions (such as BMPs and growth factors) ${ }^{16,17,26}$. (Fig. 1)

Any residual hydroxyapatite that remains after demineralization is maintained at a $10 \%-30 \%$ concentration to retain the mechanical properties of the $\mathrm{DDM}^{27}$. Demineralization widens the two types of pores in dentin: tubules and interfi- brillar spaces (collagen meshwork).(Fig. 1. B, 1. C) The total porosity of dentin increased to approximately $70 \%$ after demineralization and freeze-drying, and the degree of increase varied depending on the processing method. The porosity of dentinal tubules increased from $3 \%-6 \%$ to $20 \%$ on average (Fig. 1. B) $)^{28,29}$, whereas that of the uncollapsed, freeze-dried interfibrillar space increased to approximately $50 \%{ }^{28,29}$.(Fig. 1. C)

\section{Incorporation of rhBMP-2 with DDM (DDM/rhBMP-2)}

\section{Physical adsorption}

According to Luginbuehl et al. ${ }^{30}$, physical adsorption on a surface could be regarded as the simplest method for delivering proteins. A pre-fabricated DDM scaffold is dipped in a protein solution and left to dry. In DDM collagen without specific protein affinity, rhBMP-2 is physically adsorbed into the interfibrillar space pores on the DDM surface ${ }^{31}$.(Fig. 2; red circle) The amount of interfibrillar space porosity not deformed by freeze-drying, with a pore diameter less than $0.2 \mu \mathrm{m}$, is almost $37 \%{ }^{32}$. Given that increased porosity is a key parameter influencing adsorption, the unique geometrical shape of dentin collagen can provide a significant advantage for physical adsorption.

The dentinal tubule on the surface of DDM is also enlarged during demineralization and becomes a pore with an aver-

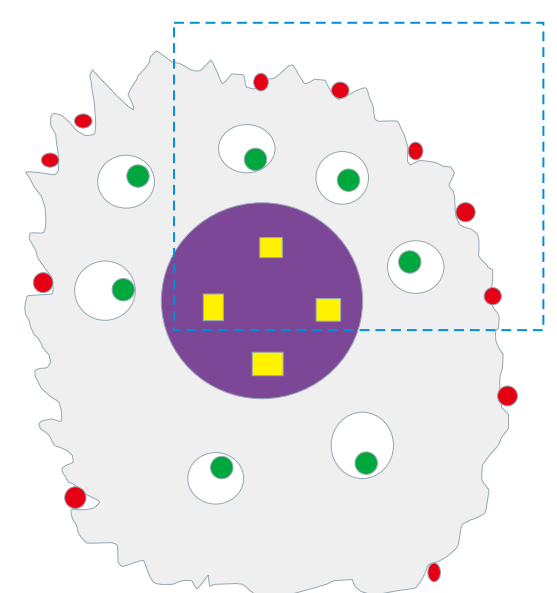

- Physically adsorbed rhBMP-2 on the loosened dentin collagen

- Physically entrapped (modified) rhBMP-2 in enlarged dentinal tubule

$\square$ Endogenous BMPs and growth factors in dentin matrix

Fig. 2. Illustration of the types of recombinant human bone morphogenetic protein-2 (rhBMP-2) incorporation with demineralized dentin matrix (DDM) (DDM/rhBMP-2). rhBMP-2 at a concentration of $0.2 \mathrm{mg} / \mathrm{mL}$ was mixed with $0.3 \mathrm{~g}$ of DDM powder, and the mixture was lyophilized $^{17,31}$. Gray: the demineralized surface of the dentin matrix, Purple: the mineralized core of the dentin matrix, Red (physical adsorption): rhBMP-2 incorporated on the surface of loosened interfibrillar space pores of the dentin collagen, Green (modified physical entrapment): rhBMP-2 incorporated into the enlarged dentinal tubule pores, Yellow (endogenous BMPs in the dental matrix): matrix- and hydroxyapatite-binding BMPs in the DDM matrix.

In-Woong Um et al: Postulated release profile of recombinant human bone morphogenetic protein-2 (rhBMP-2) from demineralized dentin matrix. J Korean Assoc Oral Maxillofac Surg 2019 
age diameter of 3-3.5 $\mu \mathrm{m}$, which is similar to the pore size of natural human bone. Therefore, rhBMP-2 is also physically adsorbed into the dentinal tubule pores located on the surface of $\mathrm{DDM}^{24}$.(Fig. 1. A, 1. B and Fig. 2; green circle)

\section{Modified physical entrapment}

Physical entrapment is achieved by mixing rhBMP-2 with a scaffold material in liquid form, causing a phase change such as gelation; this phase change induces physical entrapment of proteins within the carrier ${ }^{33}$. Mixing proteins with the ACS is a modified method where the proteins are inserted into the pores of a scaffold by dipping the ACS in a protein solution immediately before implantation (this method is used in commercially available INFUSE).

Like the ACS, denser and highly cross-linked DDM collagen allows modified entrapment of rhBMP-2, which is loaded in the pores in deeper areas of the dentinal tubule.(Fig. 1. B and Fig. 2; green circle) It has been reported that the diameter of the dentinal tubule increases to 3-3.5 $\mu \mathrm{m}$ through demineralization $^{34}$, and its porosity increases to $20 \%{ }^{29}$. As freeze-drying reduces shrinkage and decreases collagen fiber melting, rhBMP-2 is more densely entrapped in the deeper nanoporous area of the dentinal tubule and interfibrillar space pores. This structural characteristic has the advantages of preventing the initial burst release when the ACS is used ${ }^{17,23,24}$. (Fig. 2; green circle)

\section{Endogenous BMP in the DDM}

Binding of non-collagenous endogenous proteins to the dentin matrix and minerals is well established ${ }^{14,18}$. Urist suggested that, if the dentin matrix undergoes biodegradation or resorption through a remodeling process after grafting, disintegration of covalent bonding occurs and releases osteoinductive proteins, which play a key role in stimulating stem cells in the surrounding tissues and causing phenotypic changes to produce osteoblasts ${ }^{2}$. This mechanism has been determined by several in vitro and in vivo studies ${ }^{16-18,35,36}$.

Overall, DDM/rhBMP-2 contains physically adsorbed and then modified, physically entrapped rhBMP-2 and endogenous BMP that remains in the DDM as matrix and/or mineral-binding proteins.

\section{The Postulated Release Profile of rhBMP-2 from the DDM (DDM/rhBMP-2)}

The original release profile of DDM/rhBMP-2 showed sustained, slow release of rhBMP-2 over the experimental period of 36 days (Fig. 3; blue line), and a significantly larger amount of rhBMP-2 was released from the DDM powder than from any other materials ${ }^{16}$. The postulated release profile of DDM/rhBMP-2 involves sequential delivery of exogenous rhBMP-2 and endogenous BMP from the DDM in a physiological environment ${ }^{1,16}$. This sequential release profile oc-

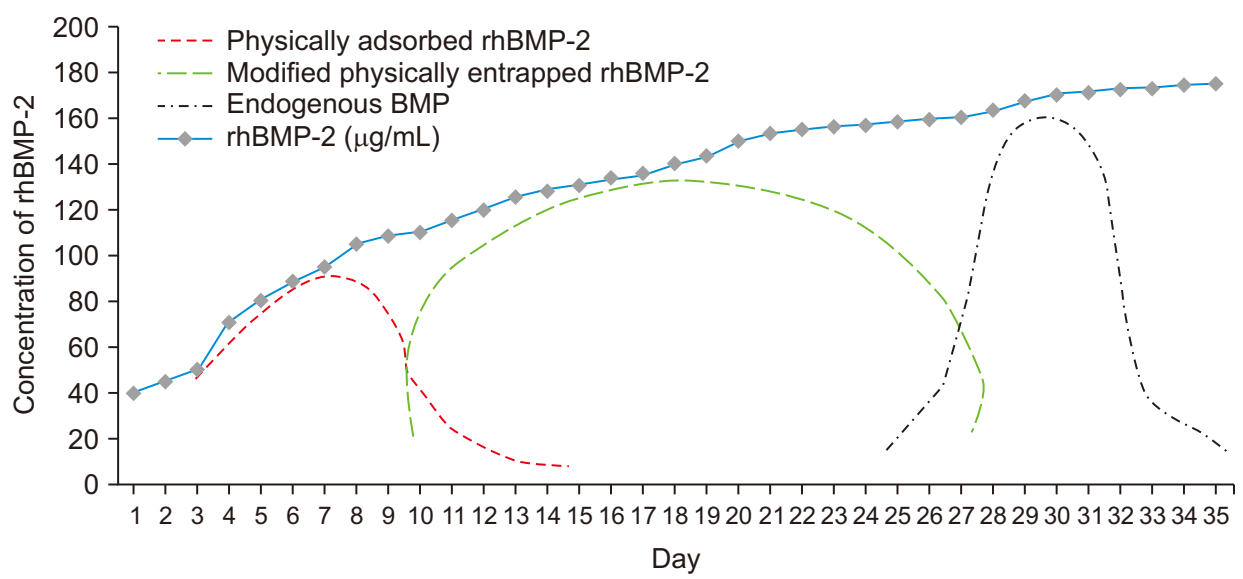

Fig. 3. An illustrative diagram of the postulated release kinetics of recombinant human bone morphogenetic protein-2 (rhBMP-2) from demineralized dentin matrix (DDM). Data from the article of Kim et al. (J Hard Tissue Biol 2014;23:415-22) ${ }^{16}$. Based on the release kinetics of rhBMP-2 from DDM, which showed a sustained release over five weeks (blue line), the postulated release profile of exogenous and endogenous proteins is displayed below the original curve (the blue line is the sum of the red, green, and black lines). The physically adsorbed rhBMP-2 on the interfibrillar space pore is released during the early stage of implantation (red line). In a subsequent stage, the modified, physically entrapped rhBMP-2 is released from the dentin matrix, which is degraded by collagenolytic or osteoclastic resorption (green line). Finally, endogenous BMPs are released with osteoclastic resorption of the remodeling process at the later stage (black line).

In-Woong Um et al: Postulated release profile of recombinant human bone morphogenetic protein-2 (rhBMP-2) from demineralized dentin matrix. J Korean Assoc Oral Maxillofac Surg 2019 
curs in the reverse order of topographical characteristics of the DDM and may be dependent on the type of incorporation of exogenous rhBMP- $2^{37}$.

In the first stage after implantation, the physically adsorbed proteins are released from the surface of the DDM collagen to induce phenotypic changes in the fibroblasts to produce osteoblasts $^{35}$.(Fig. 3; red line) Because DDM collagen is mechanically strong and the proteins are lyophilized on the collagen surface, the exogenous proteins cannot be released rapidly and resist squeezing and muscle strength, unlike the simple wetting required for ACS. Therefore, the early release profiles were slightly modified from the burst release mode assumed by El Bialy et al. ${ }^{37}$.

In the second stage, deeply entrapped proteins are released by collagen degradation ${ }^{38}$.(Fig. 3; green line) This process is accelerated via both dentinal tubule and interfibrillar space pores and is induced by collagenolytic degradation or osteoclastic resorption, which might start at the beginning of implantation but before the actual release of proteins ${ }^{1,17,36}$.

In the later stages, when osteoclastic resorption of the mineralized core of DDM proceeds as a remodeling process, release of endogenous BMP from the DDM is promoted ${ }^{17}$.(Fig. 3; black line) Thus, we adopted the release profile of covalent bonding postulated by El Bialy et al. ${ }^{37}$ for release of endogenous BMPs present as mineral and matrix-binding proteins in the DDM.

\section{Concluding Remarks}

Herein, we postulated the release profile of rhBMP-2 from the DDM according to the type of incorporation of exogenous rhBMP-2 and endogenous BMPs in the DDM as follows: 1) physically adsorbed rhBMP-2 is released during the early stage of implantation; 2) modified physically entrapped rhBMP-2 is released during the second stage; and 3) the endogenous BMPs in the DDM are released in the later stage. Considering that several side effects have been reported in association with a supraphysiologic concentration $(1.5 \mathrm{mg} /$ $\mathrm{mL}$ ) of rhBMP-2 and uncontrolled release of proteins, if the postulated sequential release profile can reduce localized complications and be effective even at a low concentration $(0.2 \mathrm{mg} / \mathrm{mL})$ of rhBMP-2, then DDM can be regarded as a potential carrier of rhBMP-2. However, there are several fundamental questions regarding the effectiveness of rhBMP at a concentration of $0.2 \mathrm{mg} / \mathrm{mL}$ instead of $1.5 \mathrm{mg} / \mathrm{mL}$ as well as the relationship between the type of incorporation and release kinetics. Further studies should be conducted to obtain more precise release kinetics and to identify a safer and more effective rhBMP-2 concentration for delivery via DDM.

\section{ORCID}

In-Woong Um, https://orcid.org/0000-0002-4628-3662

Jeong-Kui Ku, https://orcid.org/0000-0003-1192-7066

Bu Kyu Lee, https://orcid.org/0000-0001-8483-937X

Pil-Young Yun, https://orcid.org/0000-0001-6097-1229

Jeong Keun Lee, https://orcid.org/0000-0002-5561-6297

Jeong-Hun Nam, https://orcid.org/0000-0003-3957-0476

\section{Authors' Contributions}

I.W.U. and J.K.K. performed the study, participated in data collection, and wrote the manuscript. B.K.L., P.Y.Y., J.K.L., and J.H.N. analyzed the study and helped in designing the study and drafting the manuscript. All authors read and approved the final manuscript.

\section{Acknowledgements}

This study was supported by the Korea Health Industry Development Institute (grant/award No. HI15C1535).

\section{Conflict of Interest}

No potential conflict of interest relevant to this article was reported.

\section{References}

1. Urist MR. Bone: formation by autoinduction. Science $1965 ; 150$ : 893-9.

2. Urist MR, Dowell TA, Hay PH, Strates BS. Inductive substrates for bone formation. Clin Orthop Relat Res 1968;59:59-96.

3. Wozney JM, Rosen V, Celeste AJ, Mitsock LM, Whitters MJ, Kriz $\mathrm{RW}$, et al. Novel regulators of bone formation: molecular clones and activities. Science 1988;242:1528-34.

4. Reddi AH. Role of morphogenetic proteins in skeletal tissue engineering and regeneration. Nat Biotechnol 1998;16:247-52.

5. Boyne PJ, James RA. Grafting of the maxillary sinus floor with autogenous marrow and bone. J Oral Surg 1980;38:613-6.

6. Moslemi N, Khoshkam V, Rafiei SC, Bahrami N, Aslroosta H. Outcomes of alveolar ridge preservation with recombinant human bone morphogenetic protein-2: a systematic review. Implant Dent 2018;27:351-62.

7. Haidar ZS, Hamdy RC, Tabrizian M. Delivery of recombinant bone morphogenetic proteins for bone regeneration and repair. Part B: delivery systems for BMPs in orthopaedic and craniofacial tissue engineering. Biotechnol Lett 2009;31:1825-35.

8. Boyne PJ. Animal studies of application of rhBMP-2 in maxillofacial reconstruction. Bone 1996;19(1 Suppl):83S-92S.

9. Lee SH, Shin H. Matrices and scaffolds for delivery of bioactive 
molecules in bone and cartilage tissue engineering. Adv Drug Deliv Rev 2007;59:339-59.

10. Lo KW, Ulery BD, Ashe KM, Laurencin CT. Studies of bone morphogenetic protein-based surgical repair. Adv Drug Deliv Rev 2012;64:1277-91.

11. James AW, LaChaud G, Shen J, Asatrian G, Nguyen V, Zhang X, et al. A review of the clinical side effects of bone morphogenetic protein-2. Tissue Eng Part B Rev 2016;22:284-97.

12. U.S. Food and Drug Administration. Summary of safety and effectiveness data [Internet]. Silver Spring (MD): U.S. Food and Drug Administration 2007 Mar 9 [cited 2018 Dec 30]. Available from: https://www.accessdata.fda.gov/cdrh_docs/pdf5/P050053b.pdf.

13. Ike M, Urist MR. Recycled dentin root matrix for a carrier of recombinant human bone morphogenetic protein. J Oral Implantol 1998;24:124-32.

14. Murata M, Kawai T, Kawakami T, Akazawa T, Tazaki J, Ito K, et al. Human acid-insoluble dentin with BMP-2 accelerates bone induction in subcutaneous and intramuscular tissues. J Ceram Soc Jpn 2010;118:438-41.

15. Miyaji H, Kawanami M. Dentin conditioning with BMP for reconstruction of periodontal attachment. In: Murata M, Um IW, eds. Advances in oral tissue engineering. Chicago: Quintessence Publishing; 2014:19-24.

16. Kim YK, Um IW, An HJ, Kim KW, Hong KS, Murata M. Effects of demineralized dentin matrix used as an rhBMP-2 carrier for bone regeneration. J Hard Tissue Biol 2014;23:415-22.

17. Um IW, Kim YK, Jun SH, Kim MY, Cui N. Demineralized dentin matrix as a carrier of recombinant human bone morphogenetic proteins: in vivo study. J Hard Tissue Biol 2018;27:219-26.

18. Bessho K, Tanaka N, Matsumoto J, Tagawa T, Murata M. Human dentin-matrix-derived bone morphogenetic protein. J Dent Res 1991;70:171-5.

19. Murata M. Collagen biology for bone regenerative surgery. J Korean Assoc Oral Maxillofac Surg 2012;38:321-5.

20. Kim YK, Kim SG, Yun PY, Yeo IS, Jin SC, Oh JS, et al. Autogenous teeth used for bone grafting: a comparison with traditional grafting materials. Oral Surg Oral Med Oral Pathol Oral Radiol 2014;117:e39-45.

21. Pang KM, Um IW, Kim YK, Woo JM, Kim SM, Lee JH. Autogenous demineralized dentin matrix from extracted tooth for the augmentation of alveolar bone defect: a prospective randomized clinical trial in comparison with anorganic bovine bone. Clin Oral Implants Res 2017;28:809-15.

22. Schilke R, Lisson JA, Bauss O, Geurtsen W. Comparison of the number and diameter of dentinal tubules in human and bovine dentine by scanning electron microscopic investigation. Arch Oral Biol 2000;45:355-61.

23. Coutinho ET, d'Almeida JRM, Paciornik S. Evaluation of microstructural parameters of human dentin by digital image analysis. Mater Res 2007;10:153-9.

24. Goldberg M, Kulkarni AB, Young M, Boskey A. Dentin: structure, composition and mineralization. Front Biosci (Elite Ed) 2011;3:711-35.
25. Iohara K, Nakashima M, Ito M, Ishikawa M, Nakasima A, Akamine A. Dentin regeneration by dental pulp stem cell therapy with recombinant human bone morphogenetic protein 2 . J Dent Res 2004;83:590-5.

26. Kim SY, Kim YK, Park YH, Park JC, Ku JK, Um IW, et al. Evaluation of the healing potential of demineralized dentin matrix fixed with recombinant human bone morphogenetic protein-2 in bone grafts. Materials (Basel) 2017;10:E1049.

27. Kim YK, Um IW, Murata M. Tooth bank system for bone regeneration: safety report. J Hard Tissue Biol 2014;23:371-6.

28. Nakabayashi N, Pashley DH. Hybridization of dental hard tissues. Tokyo: Quintessence Publishing; 1998.

29. Garberoglio R, Brännström M. Scanning electron microscopic investigation of human dentinal tubules. Arch Oral Biol 1976;21:35562.

30. Luginbuehl V, Meinel L, Merkle HP, Gander B. Localized delivery of growth factors for bone repair. Eur J Pharm Biopharm 2004;58:197-208.

31. Um IW, Kim YK, Park JC, Lee JH. Clinical application of autogenous demineralized dentin matrix loaded with recombinant human bone morphogenetic-2 for socket preservation: a case series. Clin Implant Dent Relat Res 2019;21:4-10.

32. Vennat E, Bogicevic C, Fleureau JM, Degrange M. Demineralized dentin 3D porosity and pore size distribution using mercury porosimetry. Dent Mater 2009;25:729-35.

33. Olthof MGL, Kempen DHR, Liu X, Dadsetan M, Tryfonidou MA, Yaszemski MJ, et al. Bone morphogenetic protein-2 release profile modulates bone formation in phosphorylated hydrogel. J Tissue Eng Regen Med 2018;12:1339-51.

34. Fosse G, Saele PK, Eide R. Numerical density and distributional pattern of dentin tubules. Acta Odontol Scand 1992;50:201-10.

35. Kim KW. Bone induction by demineralized dentin matrix in nude mouse muscles. Maxillofac Plast Reconstr Surg 2014;36:50-6.

36. Tanoue R, Ohta K, Miyazono Y, Iwanaga J, Koba A, Natori T, et al. Three-dimensional ultrastructural analysis of the interface between an implanted demineralised dentin matrix and the surrounding newly formed bone. Sci Rep 2018;8:2858.

37. El Bialy I, Jiskoot W, Reza Nejadnik M. Formulation, delivery and stability of bone morphogenetic proteins for effective bone regeneration. Pharm Res 2017;34:1152-70.

38. Rumpler M, Würger T, Roschger P, Zwettler E, Sturmlechner I, Altmann P, et al. Osteoclasts on bone and dentin in vitro: mechanism of trail formation and comparison of resorption behavior. Calcif Tissue Int 2013;93:526-39.

How to cite this article: Um IW, Ku JK, Lee BK, Yun PY, Lee JK, Nam JH. Postulated release profile of recombinant human bone morphogenetic protein-2 (rhBMP-2) from demineralized dentin matrix. J Korean Assoc Oral Maxillofac Surg 2019;45:1238. https://doi.org/10.5125/jkaoms.2019.45.3.123 